Preference is given to letters commenting on contributions published recently in the JRSM. They should not exceed 300 words and should be typed double spaced

\section{Racism in the National Health Service: lessons from the past}

Dr McNaught is right to point out examples of racism in the NHS (December $2004 J R S M^{1}$ ). But what to do about it? Maybe we can learn some lessons from the past.

Today there is an over-representation of black people in the mental health system but in the 1960s Irish people were over-represented. ${ }^{2}$ Psychiatrists thought that the prevalence of schizophrenia was high in people from the west of Ireland and invented a new syndrome 'western seaboard psychosis'. ${ }^{3}$ Anthropologists descended on the unsuspecting immigrants to ask them if their Catholic faith caused their minds to unbalance and psychiatrists followed to dole out antipsychotics. But then some proper research was done and it showed no excess of schizophrenia in Irish immigrants. ${ }^{4}$ The methods of case collection in the early studies were poor and cross-cultural comparisons were not properly thought through. ${ }^{3}$

Today Irish people are no more likely to be diagnosed with schizophrenia than anyone else. How did this happen? I would love to say that it was because of the new research or because of government initiatives. The research helped a bit but the main cures for anti-Irish discrimination were that the new immigrants were richer, better educated, better informed and more questioning. They would not be fobbed off with a misdiagnosis. An increasing understanding and appreciation of Irish culture also helped reduce anti-Irish discrimination generally. The most effective cure of all was time. A cynic would add that, nowadays, people have a new batch of immigrants (such as asylum seekers) to discriminate against.

So we need fewer new policy drives and more changes of heart. These will only come from changes in society. Blaming individuals or even the NHS will not help.

\section{Kieran Walsh}

8 Elmhurst Villas, Cheltenham Road, London SE15 3AE, UK

E-mail: kmwalsh@bmjgroup.com

\section{REFERENCES}

1 McNaught A. Health policy and race equality: an illusion of progress? $J R$ Soc Med 2004;97:579-81

2 Dean G, Downing H, Shelley E. First admissions to psychiatric hospitals in south-east England in 1976 among immigrants from Ireland. BMJ (Clin Res) 1981;282:1831-3

3 Cabot MR. The incidence and prevalence of schizophrenia in the Republic of Ireland. Soc Psychiatry Psychiatr Epidemiol 1990;25:210-15

4 Commander MJ, Odell S, Sashidharan SP, Surtees PG. Psychiatric morbidity in people born in Ireland. Soc Psychiatry Psychiatr Epidemiol 1999;34:565-9

\section{Statins and micronutrients: unanswered questions}

It is refreshing to read the thoughtful editorial on this subject by Professor McKee and others (October 2004, $\left.J R S M^{1}\right)$. The interaction of micronutrients, whether administered or in deficiency states, and pharmacotherapy, is a neglected field of study in clinical pharmacology.

The logistical problems posed by studies of this nature are considerable, but suitable and willing volunteers should be relatively easy to recruit. What is necessary is the diversion of some of the energy and resources devoted to new drug assessment to research units dedicated to this sort of basic but vital understanding of the everyday use of drugs and dietary factors, including micronutrients. It may not be too fanciful to say that, from such evidence as there is available, there is scope for reduction in drug usage, with avoidance of some adverse events and alternative solutions to treatment and prevention of certain diseases.

\section{R J Walden}

Pine Lodge, 40A Titsey Road,

Limpsfield RH8 ODF, UK

E-mail: richard@walden60.fsnet.co.uk

\section{REFERENCE}

1 McKee M, Moat SJ, McDowell I. Statins and micronutrients: unanswered questions. J R Soc Med 2004;97:60

\section{Methotrexate toxicity induced by acute renal failure}

Dr Strang and Dr Pullar describe methotrexate toxicity induced by acute renal failure in two patients with rheumatoid arthritis (November 2004, JRSM $M^{1}$ ).

We had a similar experience in a patient with skin disease. Our patient was a woman of 71 who was taking methotrexate $7.5 \mathrm{mg}$ weekly for psoriasis. A flare of her psoriasis, with erythroderma, necessitated admission to hospital. She was experiencing back pain from osteoporosis, for which her general practitioner had prescribed oral morphine sulphate $20 \mathrm{mg}$ four times daily. She took her methotrexate as usual on Sunday and on Monday morning was found to be in acute renal failure (urea $37 \mathrm{mmol} / \mathrm{L}$, creatinine $384 \mu \mathrm{mol} / \mathrm{L}$, potassium $6.7 \mathrm{mmol} / \mathrm{L}$, sodium $135 \mathrm{mmol} / \mathrm{L}$ ). This was felt to be secondary to dehydration since she was drowsy, possibly because of the opioid analgesics and not eating or drinking. She later said she had avoided fluids so as not to need the toilet.

In addition to intravenous fluids she received three doses of $15 \mathrm{mg}$ folinic acid intravenously and then oral calcium folinate. Despite this, five days after taking methotrexate she became pancytopenic (haemoglobin $8.3 \mathrm{~g} / \mathrm{dL}$, white cell count $0.20 \times 10^{9} / \mathrm{L}$, neutrophils $0.02 \times 10^{9} / \mathrm{L}$, lymphocytes $0.13 \times 10^{9} / \mathrm{L}$, platelets $28 \times 10^{9} / \mathrm{L}$ ). She was transfused with blood and platelets, and was also given 
filgrastim (G-CSF). Mouth ulcers developed at the onset of pancytopenia but her skin disease virtually cleared and there was no skin ulceration. By discharge a month later her blood indices, liver function tests and renal function tests were normal. Methotrexate was restarted two months later without further incident.

\section{Christine Soon}

\section{A Ilchyshyn}

Department of Dermatology, Walsgrave Hospital,

Clifford Bridge Road, Coventry CV2 2DX, UK

\section{REFERENCE}

1 Strang A, Pullar T. Methotrexate toxicity induced by renal failure. $J R$ Soc Med 2004;97:536-7

\section{Local anaesthetic failure in joint hypermobility syndrome}

When taking biopsies to assess skin strength in EhlersDanlos syndrome type III (EDS-III), a Danish group noticed that the patients experienced much pain despite conventional local anaesthesia. ${ }^{1}$ When asked, all these patients reported previous experience of partial or complete failure of local anaesthesia in dental or obstetric procedures - for which reason some had been dismissed as hysterics. Pursuing this finding, Arendt-Nielsen et al. ${ }^{2}$ compared the effects of local anaesthesia in 8 patients with EDS-III and 8 controls. Although the patients did gain analgesia from intradermal lidocaine the duration of effect was much shorter than in controls. EDS-III (now known as EDShypermobility type) is regarded by many authorities as identical to joint hypermobility syndrome (JHS). ${ }^{3,4} \mathrm{We}$ wish to draw attention to the possibility of resistance to local anaesthesia in individuals with this common and under-diagnosed condition.

Box 1 The nine-point Beighton hypermobility score (Ref. 9) One point may be gained for each side for manoeuvres $1-4$ so that the hypermobility score will have a maximum of nine points if all are positive. A score of $\geqslant 4 / 9$ indicates widespread hypermobility

Ability to:

Passively dorsiflex the fifth metacarpophalangeal Left Right joint to $\geqslant 90^{\circ}$

Oppose the thumb to the volar aspect of the ipsilateral forearm

Hyperextend the elbow to $\geqslant 10^{\circ}$

Hyperextend the knee to $\geqslant 10^{\circ}$

Place hands flat on the floor without bending the knees

Total
Box 2 Five-part questionnaire for identifying hypermobility (Ref. 7) Answers in the affirmative to 2 or more questions suggest hypermobility with sensitivity $80-85 \%$ and specificity $80-90 \%$

- Can you now (or could you ever) place your hands flat on the floor without bending your knees?

- Can you now (or could you ever) bend your thumb to touch your forearm?

- As a child did you amuse your friends by contorting your body into strange shapes OR could you do the splits?

- As a child or teenager did your shoulder or kneecap dislocate on more than one occasion?

- Do you consider yourself double-jointed?

Box 3 Brighton criteria for joint hypermobility syndrome (JHS) (Ref. 8) $\mathrm{JHS}$ is diagnosed in the presence of two major criteria, or one major and two minor criteria, or four minor criteria. Two minor criteria will suffice where there is an unequivocally affected first-degree relative.

Major

- Beighton score of 4 out of 9 , or more (either currently or historically)

- Arthralgia for longer than 3 months in four or more joints

Minor

- A Beighton score of 1,2 or 3 out of $9(0,1,2$ or 3 if aged $50+)$

- Arthralgia in 1-3 joints, or back pain or spondylosis, spondylolysis/ spondylolisthesis

- Dislocation in more than one joint, or in one joint on more than one occasion

- Three or more soft tissue lesions (e.g. epicondylitis, tenosynovitis or bursitis)

- Marfanoid habitus (tall, slim, arm span > height, arachnodactyly)

- Skin striae, hyperextensibility, thin skin or abnormal scarring

- Eye signs: drooping eyelids, or myopia, or anti-mongoloid slant

- Varicose veins, or hernia, or uterine/rectal prolapse

Many normal people have hypermobile joints and medical diagnosis of the medical syndrome requires symptoms - which can include chronic pain, impairment of proprioception, and temporomandibular joint dysfunction (a manifestation of which dentists may be unaware). ${ }^{5}$ JHS is overrepresented in general rheumatology clinic populations and in our experience $(\mathrm{RG} \text { and } \mathrm{AJH})^{6}$ many of these patients report failure of local anaesthetics. This matter was addressed briefly in a paper published in $2003 .{ }^{7}$ A questionnaire was completed by 172 female Caucasian JHS patients, 53 non-hypermobile age-matched controls, and 28 individuals who showed evidence of hypermobility with insufficient features to qualify for JHS (HM-sine-JHS) as defined by the Brighton criteria. ${ }^{8}$ We asked 'If you have ever had a local anaesthetic injection (dentist/minor surgery/epidural), did you think that it was as effective as it should have been?'. $58 \%$ of JHS patients, $21 \%$ of controls and $14 \%$ of the HM-sine-JHS group answered in the negative. For JHS versus controls the odds ratio was a highly significant 2.85. Although the question was simplistic, non-exploratory, and reliant on recall and self- 
perception, the difference between JHS and controls was striking. Neither group had knowledge of any study hypothesis. At the time there was nothing of this nature documented in patient information sheets or published research.

We suspect that in many people JHS goes unrecognized. So, how can a busy clinician, mindful of possible resistance to local anaesthesia, make the diagnosis? There are two easy methods for identifying hypermobility - carry out a Beighton score ${ }^{9}$ (Box 1); or ask the patient to answer a five-part screening questionnaire $^{7}$ (Box 2). The phenotype is shown in Box 3.

Although the pathophysiology of this phenomenon remains unresolved, an important clue that a patient is at risk of local anaesthetic failure might be in front of our eyes.

\section{Alan J Hakim, Rodney Grahame}

Centre for Rheumatology, University College London Hospitals, London, UK

\section{Paul Norris, Colin Hopper}

Department of Oral Surgery, University College London Hospitals, London, UK

Correspondence to: Professor R Grahame, The Hypermobility Clinic, Centre for Rheumatology, UCL Hospitals, 4th Floor, Arthur Stanley House, 40-50 Tottenham Street, London W1T 4NJ, UK

E-mail: rodneygrahame@aol.com

\section{REFERENCES}

1 Kaalund S, Hogsaa B, Grevy C, Oxlund H. Reduced strength of skin in Ehlers-Danlos syndrome type III. Scand J Rheumat Dis 1990;19:67-70

2 Arendt-Nielsen L, Kaalund S, Bjerring P, Hogsaa B. Insufficient effect of local analgesics in Ehlers Danlos type III patients (connective tissue disorder). Acta Anaesth Scand 1990;34:358-61

3 Grahame R. Joint hypermobility and genetic collagen disorders: are they related? Arch Dis Childh 1999;80:188-91

4 Zweers MC, Kucharekova M, Schalkwijk J. Tenascin-X: a candidate gene for benign joint hypermobility syndrome and hypermobility type Ehlers-Danlos syndrome? Ann Rheumat Dis (in press)

5 Buckingham RB, Braun T, Harinstein DA, et al. Temporomandibular joint dysfunction syndrome: a close association with systemic joint laxity (the hypermobile joint syndrome). Oral Surg Oral Med Oral Pathol 1991;72:514-19

6 Grahame R, Hakim AJ. High prevalence of joint hypermobility syndrome in clinic referrals to a north London community hospital. Rheumatology 2004;43 (suppl 2):91

7 Hakim AJ, Grahame R. A simple questionnaire to detect hypermobility: an adjunct to the assessment of patients with diffuse musculoskeletal pain. Int J Clin Practice 2003;57:163-6

8 Grahame R, Bird HA, Child A, et al. The revised (Brighton 1998) criteria for the diagnosis of benign joint hypermobility syndrome (BJHS). J Rheumatol 2000;27:1777-9

9 Beighton PH, Solomon L, Soskolne CL. Articular mobility in an African population. Ann Rheumat Dis 1973;32:413-17

\section{Appendicitis after appendicectomy}

Dr Clark and Mr Theodorou describe a case of distal appendicitis following difficult appendicectomy in a young woman (November 2004, $J R S M^{1}$ ). As they say, the proximal stump is the more usual site for recurrence. The distal appendix can be left behind in the technically demanding operation of retrograde appendicectomy when the organ is subhepatic and retrocaecal. ${ }^{2}$ Distal appendix can also be left behind when duplex appendix ${ }^{3}$ is not identified by the surgeon - especially likely to happen when the operation is performed through a small Lanz incision. ${ }^{4}$ Necrosis at the base of appendix due to impacted faecolith could lead to separation of the distal part during surgery. A long pelvic appendix ${ }^{5}$ with inflamed tip often adheres to viscera deep inside the pelvis, and the adherent distal part may be left behind if the surgeon is not vigilant. Before abdominal wound closure it is advisable to examine the excised specimen to ensure complete removal, particularly after technically difficult appendicectomy (subhepatic appendix, very long retrocaecal appendix, obese patient, necrotizing appendicitis). If there is doubt about complete removal, the incision may have to be extended to allow thorough inspection.

\section{K H Ravi Kumar}

\section{Ali Thwaini}

Department of Surgery,

Watford General Hospital, Watford WD18 OHB, UK

\section{REFERENCES}

1 Clark J, Theodorou N. Appendicitis after appendicectomy. J R Soc Med 2004;97:543-4

2 Ker H. Retrograde appendicectomy. Lancet 1964;22:889

3 Narula IM, Pendse AK, Dandia SD. Appendix duplex. Int Surg 1974;59:173-4

4 Schumpelick V, Dreuw B. Appendix and caecum-embryology, anatomy and surgical applications. Surg Clin N Am 2000;80:295-318

5 Wakeley CPG. Position of the vermiform appendix as ascertained by analysis of 10,000 cases. J Anat 1933;67:277

\section{Familial proptosis and obesity in the Ptolemies}

The Macedonian family of the Ptolemies (or Lagid dynasty) ruled Ancient Egypt from $323 \mathrm{BCE}$ to $30 \mathrm{BCE}$, coming to power after the death of Alexander the Great. On coins and on sculptures, portrayals of members of this dynasty are notable for prominent eyes and necks, ${ }^{1}$ and these features have been interpreted as representing familial Graves' disease (Figure 1). However, in addition the dynasty was

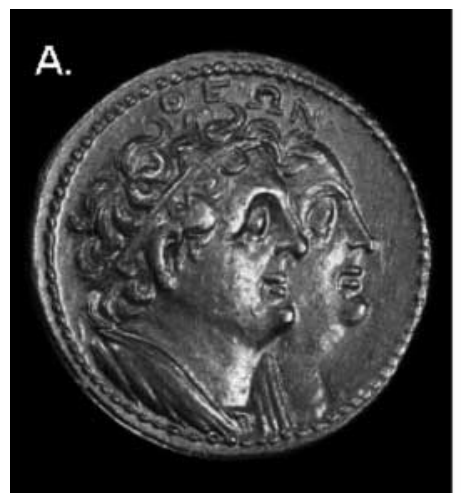

B.

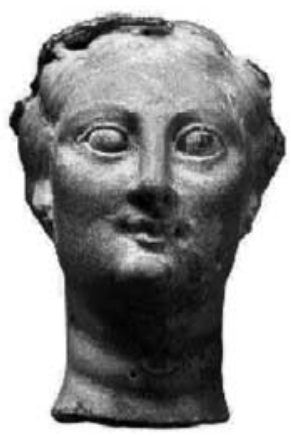

Figure 1 Ptolemy II Philadelphus depicted on a coin (A) with his sister/wife Arsinoe II, who is also represented in the sculpture (B) British Museum, London. 
noted for consanguinity and a strong family history of morbid obesity. ${ }^{2}$ These features have not hitherto been linked. Obesity is not a likely accompaniment of untreated hyperthyroidism, so what are the other possibilities? Craniosynostoses causing exophthalmos are unlikely in the absence of other craniofacial abnormalities; and proptosis in this family might be secondary to the obesity ${ }^{3}$ or even to familial amyloid with intraorbital involvement. The presence of neck masses, I suggest, may implicate a multiorgan fibrotic condition such as Erdheim-Chester disease or familial multifocal fibrosclerosis in which thyroiditis can coincide with obesity and proptosis. ${ }^{4}$

\section{Hutan Ashrafian}

Department of Surgery,

St Mary's Hospital, London W2 1NY, UK

\section{REFERENCES}

1 Stanwick PE. Portraits of the Ptolemies: Greek Kings as Egyptian Pharaohs. Austin: University of Texas Press, 2002

2 Michalopoulos A, Tzelepis G, Geroulanos S. Morbid obesity and hypersomnolence in several members of an ancient royal family. Thorax 2003;58:281-2

3 Smolders MH, Graniewski-Wijnands HS, Meinders AE, Fogteloo AJ, Pijl H, de Keizer RJ. Exophthalmos in obesity. Ophthalmic Res 2004; 36:78-81

4 Egsgaard Nielsen V, Hecht P, Krogdahl AS, Andersen PB, Hegedus L. A rare case of orbital involvement in Riedel's thyroiditis. J Endocrinol Invest 2003; 26: 1032-6

\section{Methicillin-resistant Staphylococcus aureus in intensive care units}

Dr Thompson (November 2004, JRSM $M^{1}$ ) describes the measures taken to prevent MRSA infection in the intensive care unit of Medway Maritime Hospital.

An additional strategy at St Thomas' Hospital is to bathe patients daily using chlorhexidine gluconate scrub. In patients whose nasal and/or groin swabs grow MRSA, mupirocin nasal ointment is given for five days. After two days, patients with previously positive swabs are rescreened. After three clear screens the patient may leave isolation and is screened weekly. Skin decontamination may be a helpful measure to reduce MRSA in the intensive care unit, especially in view of Thompson's observation that length of stay predicts acquisition.

\section{Suneeta Kochhar \\ Stephen French \\ St Thomas Hospital, \\ London, UK}

\section{REFERENCE}

1 Thompson DS. Methicillin-resistant Staphylococcus aureus in a general intensive care unit. J R Soc Med 2004;97:521-6

\section{Compulsory helmets for cyclists}

Professor Gandevia (December 2004 JRSM'1) says 'Wearing helmets by all cyclists should also seem common sense'. Diffidently, I suggest that common sense dictates the use of protection, but not necessarily protection with a helmet. There are a few million Sikhs of the 'Keshadhari' faith. They wear their hair long, with a turban. A helmet over a turban would be hard to wear. As there are hundreds of thousands such Sikhs in Europe and Australia - and they do use the push-bike amongst other modes of transport - it should be possible to conduct an epidemiological study of the value of the turban in protecting against head injury. On a historical (and legal) note: Lord Devlin gave judgment some forty years ago in favour of a Sikh motorcyclist who refused to wear a helmet.

J K Anand

3 Wayford Close, Peterborough PE3 9NL, UK

\section{REFERENCE}

1 Gandevia S. Compulsory helmets for cyclists. J R Soc Med 2004;97:612

\section{Coxibs and caution}

Dr Yoong (December $2004 J R S M^{1}$ ) suggests that, in view of the adverse cardiovascular effects of rofecoxib and the possibility of a class effect of related drugs, there is a case for considering older agents such as diclofenac (together with a proton pump inhibitor). I have taken rofecoxib since it became available in 1999. Very soon I was aware that the benefit from rofecoxib is not proportionate to the dosage, albeit that could be the case in the prevention of colonic polyps. From the outset I was aware of a theoretical cardiovascular risk, which I discounted since I have ingested fish oils daily for many years. I also knew of the possibility of sodium retention causing a rise of blood pressure (for which the mechanism has recently been clarified $^{2}$ ) and found myself taking hypotensive agents and trying to adhere to a low sodium diet.

I am devastated by the withdrawal of rofecoxib, which is clearly safe for me, because for other good reasons I have not yet found an adequate substitute. I am thus not now as active as I should be. I have to say also that for years I have been worried by the way many rheumatologists have prescribed coxibs and organized clinical trials of coxibs without monitoring recipients' blood pressure and fluid status.

\section{E N Wardle}

17 Downlands, Baldock, Herts SG7 6SY, UK

E-mail: nigel@edwinwardle.freeserve.co.uk

\section{REFERENCES}

1 Yoong JKC. Coxibs and serious adverse cardiovascular events: a classeffect? J R Soc Med 2004;97:609

2 Zewde T, Mattson DL. Inhibition of cyclooxygenase 2 in the rat renal medulla leads to sodium-sensitive hypertension. Hypertension 2004;44: $424-8$ 


\section{The Renaissance fifth finger}

Dr Hijmans and Dr Dequeker (November $2004 J R S M^{1}$ ) have presented five 15th century paintings by Dirk Bouts (1410-1475) and his son, Albrecht. Each of these portrays a woman with a distinct deformity of one or both fifth fingers. They have proposed that a single sitter for all of these portraits had camptodactyly, a congenital, often hereditary, fixed flexion of the proximal interphalangeal (PIP) joint of the fifth finger but without flexion of the distal interphalangeal (DIP) joint. This is accompanied by compensatory hyperextension of the metacarpophalangeal joint. $^{2}$ This conformation of the fifth finger is not physiological. That is, most people cannot flex the PIP joint of the fifth finger without also flexing the DIP joint. It is reasonable, then, to suggest a pathological basis for the fingers in the portraits.

Hijmans and Dequeker dismiss 'mannerism' as an explanation, having found no such anomalies in works by other artists of the time. However, I have come across several camptodactyly-like hands in The Metropolitan

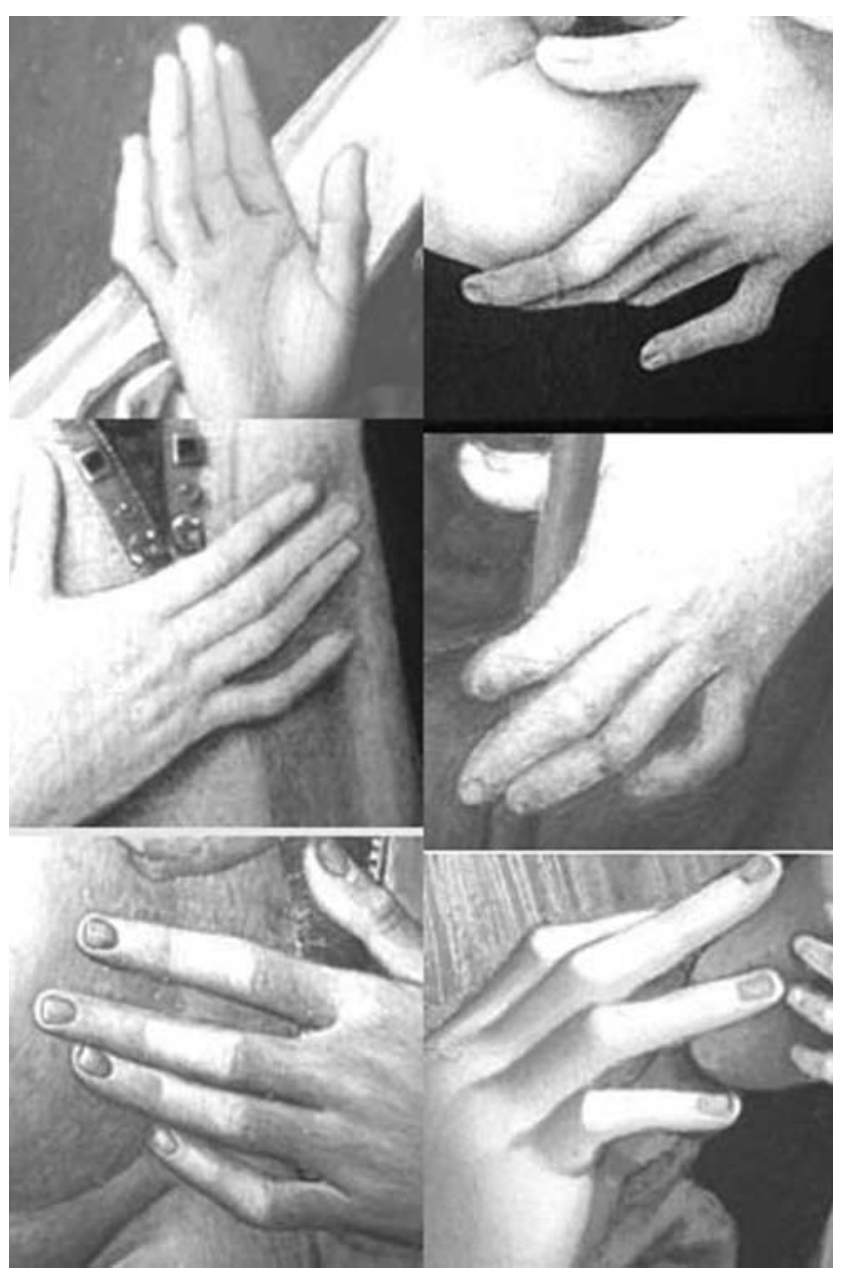

Figure 1 Renaissance hands from the Metropolitan Museum of Art
Museum of Art. Some examples are shown in Figure 1. The artists are, reading left to right from top to bottom, Gerard David (1455-1523), Fillipo Lipi (1406-1469), Hans Memling ((1430-1494), Pietro Perugino (1448-1523), Cosimo Roselli (1439-1507), and Luca Signorelli (14451523). It seems that both northern and southern European artists from roughly 1420 to 1520 used this unphysiological affectation, perhaps to imbue the hand with a certain delicacy and grace.

I suggest that Dirk Bouts and his son were not using a sitter with a pathological deformity, but were simply following the fashion of the time.

\section{Horton A Johnson}

160 West 66th Street, \#47C, New York, NY 10023, USA

E-mail: horton_Johnson@hotmail.com

\section{REFERENCES}

1 Hijmans W, Dequeker J. Camptodactyly in a painting by Dirk Bouts (c. 1410-1475). J R Soc Med 2004;97:549-51

2 Wood VE. Camptodactyly. In: Green DP, ed. Operative Hand Surgery, 2nd edn. New York: Churchill Livingstone, 1988:409-10

\section{Authors' response}

Dr Johnson's examples from the Metropolitan Museum of Art show hyperextension of the metacarpophalangeal joint of the fifth finger in combination with flexion of the proximal interphalangeal joint, but do not present a hyperextension of the distal interphalangeal joint. In two examples a flexion of the peripheral joint can be observed. The criteria of camptodactyly are therefore not met. A stylistic trait, the hallmark of this period, is that the fingers are fine and long, the middle and fourth finger close together and the little finger portrayed with a crooked deformity (clinodactyly). These features are prominent in art works of the school of Rogier van der Weyden in Flanders and of Sandro Botticello in Italy. As mentiond by Dr Johnson, these features can add grace and delicacy. This could well be the case in the picture by a follower of Dirk Bouts (our Figure 7), where the fingers were 'corrected'. The presentation of the fifth fingers in the elderly lady (our Figure 6) are logically explained by the combination of age and disease.

\author{
W Hijmans ${ }^{1}$ \\ J Dequeker ${ }^{2}$ \\ ${ }^{1}$ University of Leiden, The Netherlands; ${ }^{2}$ University of Leuven, Belgium
}

\section{REFERENCE}

1 Dequeker J. Medicine Seen Through the Eyes of The Artist. Leuven: Davidsfonds (in press) 


\section{CORRECTION}

Incidence of fatigue symptoms and diagnoses presenting in UK primary care from 1990 to 2001

We regret that Figures 2 and 4 in this paper (December $2004 J R S M^{1}$ ) were printed wrongly. The correct versions are below. Also, the year in reference 26 should be 2001 .

\section{REFERENCE}

1 Gallagher AM, Thomas JM, Hamilton WT, White PD. Incidence of fatigue symptoms and diagnoses presenting in UK primary care from 1990 to 2001. J R Soc Med 2004;97:571-5

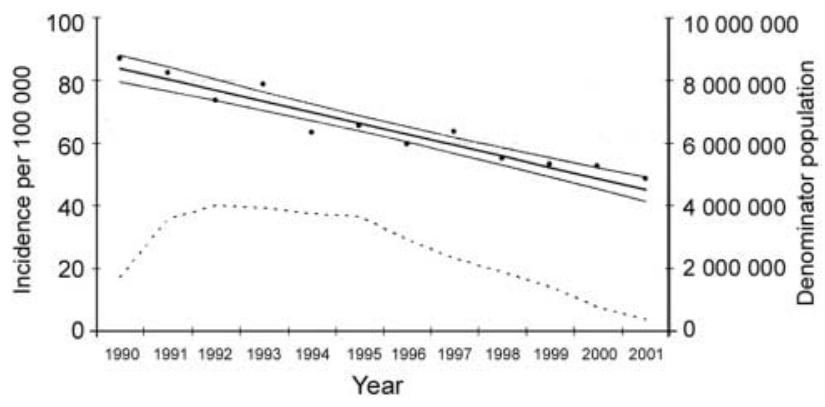

Figure 2 Incidence of all fatigue diagnoses, excluding fibromyalgia [Symbols as in Figure 1]

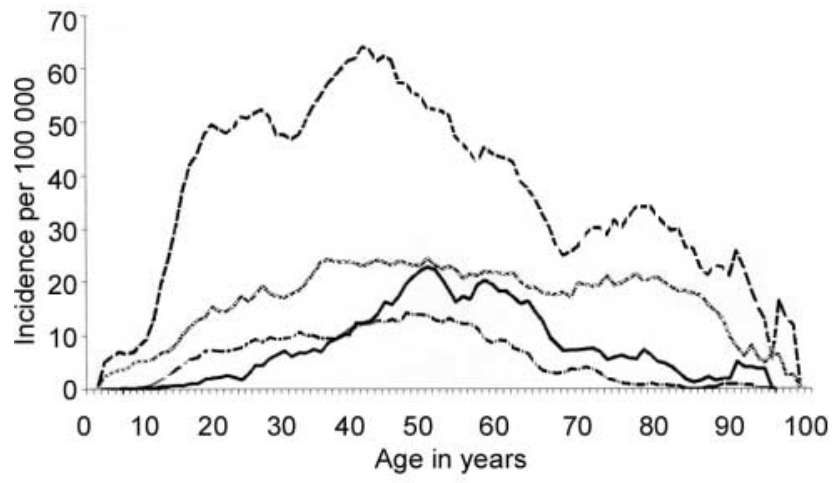

Figure 4 Age-specific incidence (5-year moving average).

[- - - Postviral fatigue syndrome; …....... debility/asthenia;

- - - chronic fatigue syndrome/myalgic encephalomyelitis;

fibromyalgia 